\title{
Potential impact of climate change effects on preferences for tourism destinations. A psychological pilot study
}

\author{
Ottmar L. Braun 1,*, Martin Lohmann², Olga Maksimovic ${ }^{1}$, Martin M eyer ${ }^{1}$, \\ Anetta Merkovic ${ }^{1}$, Eva Messerschmidt' ${ }^{1}$, Annette Riedel ${ }^{1}$, M arcella Turner ${ }^{1}$
}

${ }^{1}$ Universität Koblenz-Landau, Fachbereich 8: Psychologie, Im Fort 7, D-76829 Landau, Germany

${ }^{2}$ N .I.T. Kiel, Schaßstraße 5, D-24103 Kiel, Germany

\begin{abstract}
This paper is intended to demonstrate the usefulness of a psychological experimental approach in researching the underlying processes of socio-economic impacts of the effects of an eventual climate change in the field of tourism. Tourism demand for the German coasts at the North and Baltic Seas may be influenced in some way by climate change impacts, e.g. by new preferences for holiday destinations due to changing environmental conditions (especially weather) and due to the actions taken by the tourism industry to cope with these changes. A pilot study was designed and carried out in order to develop a method to measure the sensitivity of destination choice to climate change effects and to gain first ideas of whether and how destination preferences will probably change. 136 subjects in 5 experimental conditions were given scenarios describing 'positive' or 'negative' climate change effects with and without (re)actions of the regional tourism industry. The control group received a scenario describing no changes. Subjects interest in spending a holiday at the North Sea and Baltic Sea in Germany were defined as the dependent variable. One of the crucial aspects was to check whether the applied technique is appropriate for making the situation, which is only a hypothetical and future one, sufficiently clear (make it feel 'real') to the participants in the study. The methodological approach is suitable for further (and more in depth) research: subjects had no trouble imagining the scenarios. The manipulation checks indicated differences, and differences between conditions were also found in the dependent variables. Thus, the adopted procedure appears promising and can be applied in future studies. Nevertheless, some improvements are recommended. Within the restricted possibilities of a pilot study, first ideas on whether and in which direction the effects of an eventual climate change may influence destination choice of tourists are presented. According to the data, climate change can influence the preferences for vacation destinations. With respect to the North German coastal region, this effect is rather a negative one. Under the climate change conditions presented in the scenarios, possible tourists are less eager to travel there than under today's conditions. It will not be easy for the local and regional tourism industry to reduce negative effects or to use positive effects to a certain extent by appropriate action. Within limits this possibility may exist, but one has to be rather careful in defining what is 'appropriate', e.g. with respect to their target groups in tourism. The results still do not allow for predictions of destination choice or behaviour patterns during holidays. The experimental method described here may be one additional tool to the many others used to gain a clearer picture of a possible future of tourism in coastal areas under climate change conditions.
\end{abstract}

KEY WORDS: Climate change $\cdot$ Coastal tourism - Vacation destination choice $\cdot$ Climate perception . Scenario technique

\section{INTRODUCTION}

Results of climate change research (cf. Houghton et al. 1996) show that the greenhouse effect has been intensified by man by increasing the concentration of

*E-mail: braun@uni-landau.de carbon dioxide in the earth's atmosphere. According to the prediction of climate models, this development is accompanied by a rise in global average temperature. This has a number of further consequences which are the subject of climate change impact research. Possible effects are, for example, the rise of sea level or changes in vegetation. As far as the magnitude of these effects 
or regional effects are concerned, no reliable data are yet available. In addition to physical, geological, and ecological changes, it is also necessary to consider sociological and psychological aspects, such as who perceives climate change, how do individuals perceive climate change, and how do they respond to their perceptions of changes (for example, adaptive behaviour, avoidance strategies), in order to assess societal effects of climate change (cf. Stehr \& von Storch 1995).

NIT, the Institute for Tourism and Recreational Research in Northern Europe, Kiel (Germany), in cooperation with the Department of Psychology at the University of Koblenz-Landau (Germany) conducted the psychological experiment presented here as a pilot study in the scope of the extensive social scientific research program 'Coastal Tourism and Climate Change', commissioned by the German Ministry of Education, Science, Research, and Technology. The focus of this research is the question of which direction tourism could take with regard to the German coastal region under different conditions of climate change. Similar research has been carried out for other types of destinations, e.g. the Alps (A begg 1996).

Coastal areas at the North and Baltic Seas in Germany are one of the most important tourist destinations in Germany (Aderhold 1998, Lohmann et al. 1998) and tourism is the most important source of income for the region (Feige et al. 1998, p. 61).

The objective of the pilot study was to investigate how possible climate change effects may influence the choice of a vacation destination. Furthermore, a methodological question studied was to see if the applied technique was appropriate for making the situation, which is only a hypothetical and future one, sufficiently clear to the participants in the study. For the purpose of the experiment we had to reduce the rather complex reality to a rather restricted set of variables.

\section{THEORETICAL BACKGROUND}

The focus of the experiment is on how a given set of information presented to the subjects will change their expressed preferences for holiday destinations. The decision process itself (how do people choose a holiday destination?) is not a subject of the study. We may regard it as a kind of black box. The information on how the destination will look like under different climate change conditions is presented as an input, the destination preferences are registered as the output. Nevertheless we had to consider the important factors influencing travel decisions in order to create a realistic input.

A central contribution to understanding decision processes underlying vacation trips is the work of Hahn \& Hartman (1973). According to their research results and conclusions, besides the general question of whether one should take a trip at all, the decision to travel depends upon the factors (or sub-decisions) destination, type of vacation, price, type of accommodation, means of transportation, and organisation of vacation trip.

To date, a theory - or a number of rivalling theories - of travel decision is lacking (Braun \& Lohmann 1989), and so the respective studies (e.g. Hartmann 1978, Pivonas 1980, Purucker 1986) generally do not get beyond the exploratory stage. The whole area involving which criteria (including climate-related criteria) people use to make decisions about tourism or recreation choices is largely unresearched but highly relevant to a variety of applications.

However, available descriptive data (Lohmann \& Wohlmann 1987, Braun \& Lohmann 1989, Forschungsgemeinschaft Urlaub und Reisen 1996) provides the following research findings and conclusions relevant to the question under study here:

(1) Provided that one has decided to go on a trip, the choice of destination is one of the most important subsequent (sub-)decisions. It often takes place at the beginning of the decision process.

(2) The choice for or against a destination is influenced by the factors attractiveness (e.g. nature, landscape, places of cultural interest), available facilities (of importance to tourists, such as accommodations) and accessibility (e.g. good means of transportation) (cf. Holloway 1994).

(3) To a certain degree, vacation destinations can compensate for deficits in one of the factors (e.g. accessibility) with advantages in another (e.g. attractiveness).

(4) In many cases, the decision of the vacationer is based upon an image resulting from information provided by third persons, and not upon 'true' and actual experiences.

(5) Climate and weather are important factors in choice of destination. These factors (and/or the respective images people have in mind, i.e. the psychological representation of weather) influence the attractiveness of a potential vacation region (good weather and plenty of sunshine are among the most important expectations in connection with vacations), require or enable certain kinds of facilities to be offered at the destination, and can also have an effect on accessibility, depending on the time of the trip.

Climate change effects could have an influence on the 3 aspects mentioned above in (2), either directly or indirectly (through reactions of the persons concerned): attractiveness, e.g. a slight increase of the air and water temperature during summer could increase the attractiveness of the North German coastal region 
as a vacation destination; available facilities, e.g. a higher probability of precipitation could lead to an increase in weather-independent recreational facilities, such as indoor fun pools; and accessibility, e.g. a higher sea level could threaten the existing infrastructure, e.g. destruction of roads.

As climate change will be manifested in weather this is one of the most important factors with potential influence on tourist behaviour. Clawson (1966) stressed that a lot of leisure activities depend on certain weather conditions, mainly described by temperature, duration of sunshine, wind and rain. Nicely warm, but not too hot, sunshine and no rain and a light wind seems to be the leisure activity optimum. De Freitas (1990) supported her statements by proving that the number of beach visitors in King's Beach, Queensland, Australia, depends on 3 main factors: the subjective representation of air temperature (optimum somewhere between neutral and warm), wind (with an optimum velocity below $6 \mathrm{~m} \mathrm{~s}^{-1}$ ) and clouds (covering less then $30 \%$ of the sky). This study showed which of the components constituting 'the weather' are crucial for visits to a beach. Within this context the importance of weather forecasts in the planning and decision of leisure activities is obvious. For a tourist destination, weather is one of the unstable characteristics changing in short intervals. Based on Festinger's theory of cognitive dissonance Adams (1973) showed for New England, USA, beach visitors that weather forecasts are paid a maximum of attention when the decision of whether to go to the beach or not is only preliminarily taken. If the plans are already fixed, the weather information is often ignored.

Clawson (1966, p. 190) reflected on a potential change of climate: 'If weather modifications were large enough, regular enough, and dependable enough, it would modify the basic or general climate to some extent, and thus have some effect upon outdoor recreation, both as to kinds of activities and as to levels of participation in various activities... The effects of such major modification in weather as to be virtually a change in climate would be felt both upon the natural environment and upon the recreationist in his use of that environment. ... Lacking precise information on the kinds of major weather modification, one cannot readily say much about their effects; but, in any case, such truly major weather changes are presently highly improbable.'

Since 'bad' weather may lead to a reduced tourist demand, suggestions for means of compensation are welcomed. Clawson (1966) recommended some of the reactions we later used in our scenarios to describe the action of the tourism industry, e.g. air-conditioning, covered areas to protect people from rain or too much sunshine, appropriate clothing, etc. Clawson (1966, p. 193) states: 'While much can possibly be done to reduce the unfavourable aspects of generally unattractive weather, yet it must also be recognised that the same scientific and technological forces which would permit insulating outdoor recreationists from some measure of unfavourable weather would also make it possible to have more attractive indoor recreation.'

In his studies, Krupp (1995) attempted to acquire a better understanding of the responses of the local and regional tourism industry in the socio-economic climate change effect reaction. He focussed not only on particular action options (e.g. to build an indoor swimming pool), but also included rather implicit action-relevant models. The method he chose was the presentation of scenarios in group discussions. These scenarios contained physical and meteorological climate change effects, possible responses of vacationers, and a degree of uncertainty as to the question of whether the observed changes in nature really are indicators or effects of serious climate change. The pilot study presented here attempts to apply this procedure to vacationers with consideration of the research findings described above.

Obviously, destination choice is influenced by holiday motivation or the preferred kind of vacation. Depending on motivation, different destinations are preferred (cf. Aderhold 1997), because the expected satisfaction of different needs varies according to destination and motivation (van Raaij \& Francken 1984). With reference to the German coastal region, the motive of (undisturbed) rest and relaxation (cf. Mundt \& Lohmann 1988) plays a significant role (Lohmann et al. 1998, p. 74). Here, the question arises of whether the expected need satisfaction is influenced by possible climate change effects, thus causing a change in destination choices to be an interaction effect.

The pilot study was designed to take account of these considerations. Subjects first received a selfreport questionnaire requesting them to rate the importance of different vacation motives/activities. Then they read a short text describing a scenario in 5 different versions (5 experimental conditions; for details, see Section 3). The scenarios were based upon publications dealing with climate change and global warming (e.g. Krupp 1995) and further developed with plausible assumptions of what the future could bring. The scenarios are fictitious; they are designed to show qualitative potential possibilities and in no case to be interpreted as representative of predictions. The probability that a specific region would be chosen as destination in the scenario condition was the main dependent variable.

Three hypotheses were formulated for this study. The main question is how the likelihood to visit a tourist destination at the North Sea or Baltic Sea varies de- 
pending upon climate change scenarios in comparison to a control group. The control group received a scenario describing no changes from the current situation.

Hypothesis 1: It is expected that the reported likelihood to visit a tourist destination increases in the case of the so-called 'positive' scenarios in comparison to a control group. In the positive scenarios the climate becomes similar to that of the M editerranean area.

Hypothesis 2: It is expected that the reported likelihood to visit a tourist destination decreases in the case of the so-called 'negative' scenarios. In the negative scenarios effects of climate change involve more rainfall and storms as well as radical ecological changes.

Hypothesis 3: The effects of negative scenarios can be compensated by adequate responses of the regional tourism industry.

\section{METHOD}

\subsection{Subjects and procedure}

For the purpose of the pilot study, students at the Department of Psychology of the University of KoblenzLandau distributed 160 questionnaires among their friends and acquaintances and collected them again a few days later. A requirement was that subjects travelled at least once a year. The return rate was $85 \%$ (136 completed questionnaires).

The majority of this non-representative sample were young adults ( $70 \%$ were between 20 and $39 \mathrm{yr}$ old), either living with their parents or alone (66\%). $58 \%$ were female.

\subsection{Questionnaire and design}

\subsubsection{Preferred activities}

To test the hypotheses, a questionnaire experiment was conducted. Prior to presenting 1 of 5 scenarios to the participants, the importance of relaxation was assessed with the following question: 'How important are the following activities for you when on vacation?'. Subjects were presented a list of 12 activities/motives including 'rest and relaxation'. Each activity or each motive was rated on a 4-point rating scale ranging from 1 (not important at all) to 4 (very important).

\subsubsection{Scenarios}

Next, 1 of 5 scenarios describing a possible climate change and tourism industry responses was presented in written form (between-subject design).
(1) No change of climate (control group): 'Please read the following excerpt on findings of climate research taken from the "Journal of Climatic Sciences" (1995). Changes in climate will hardly worsen the already existing problems in the Mediterranean area. Average temperatures will rise only slightly. The weather at the North Sea and Baltic Sea will not be much different than it is today. The higher temperatures observed during the last few years should not be taken as an indication of global warming. These climatic changes reflect natural fluctuations. Therefore, we can assume that the climate both at the coasts and inland will be about the same as it is today. In other words, we will still have good summers, but it is also possible that a summer will be rainy throughout.'

(2) Negative effects/without tourism industry responses: 'Please read the following excerpt on findings of climate research taken from the "J ournal of Climatic Sciences" (1995). Changes in climate will hardly worsen the already existing problems in the Mediterranean area. Average temperatures will rise only slightly. Due to global warming the polar caps will melt, causing a rise of the sea level, especially in the North Sea and Baltic Sea. This will spark off a chain reaction: higher humidity, increased cloud formation, monsoon-like rainfall, and permanent danger of storms during spring and fall culminating in real storm tides as the sea level continues to rise. The stronger ultraviolet rays will cause the plankton in the oceans to die. Due to the fact that the lowest member in the ocean food chain is missing, far-reaching ecological changes will occur. There is a great danger that the North and Baltic Seas will turn into a "Dead Sea", also because of present pollution problems due to disposal of waste water.'

(3) Negative effects/ with tourism industry response: Same text as in (2) but with the following supplementary information: 'In order to cope with the higher danger of storm tides, guest houses, hotels, and campsites will be relocated further inland. Free transportation to the beach will be offered to tourists and health resort visitors by means of shuttle buses. A broad spectrum of indoor activities will be offered, such as roller-skating rinks, indoor tennis, indoor climbing facilities, and sports centres. In particular, many salt water swimming pools will open up. Cultural leisure-time activities will increase: there will be more movie theatres, concert halls, discos, and shows with regional character presented by the local people.'

(4) Positive effects/ without tourism industry response: 'Please read the following excerpt on findings of climate research taken from the "J ournal of Climatic Sciences" (1995). Changes in climate will hardly worsen the already existing problems in the Mediterranean area. Average temperatures will rise only slightly. 
Global warming will be accompanied by a corresponding rise in water temperature. In particular at the North Sea and Baltic Sea, temperatures will become much warmer. There will be a greater number of sunny days per year. Short, refreshing rain showers will occur only occasionally. Thus, the vegetation will gradually become more Mediterranean-like.'

(5) Positive effects/with tourism industry response: Same text as in (4) but with the following supplementary information: 'The hotels at the North Sea and Baltic Sea will all be fully air-conditioned and offer more leisure activities, such as sea-kayaking, surfing, beach volleyball, cutter trips, and beach parties. The states and communities will extend cycle tracks and hiking trails. Because of the good weather, a broader variety of open-air activities will be offered for children (beach rallies, fun Olympics, horseback-riding).The Mediterranean-like climate will allow carnivals and open-air festivals to take place; it will be possible to hold such events even in spring and fall without having to worry about the weather. Even the promenades will offer more attractions than today, which hardly goes beyond sitting down somewhere, enjoying the view, and having a cup of coffee.'

\subsubsection{Manipulation check}

The presentation of the scenarios was followed by a manipulation check which involved 2 aspects: (1) the question of whether the subjects were able to imagine the described situation and (2) the question of whether they rated the described changes positively or negatively for the respective region and from a global perspective. These questions were phrased as follows:

'How easy or hard is it for you to imagine the situation described above?' (4-point-scale: $1=$ very easy; 2 = easy; 3 = difficult; 4 =impossible)

'How positive or negative do you think the described changes are for the particular region?' (5-point-scale: 1 = positive, 2 =rather positive; $3=$ neither positive nor negative; $4=$ rather negative; $5=$ negative)

'How positive or negative do you think the described changes are for the earth as a whole?' (5-point-scale as above)

\subsubsection{Dependent variable}

Following the manipulation check, the likelihood of visiting various destinations was assessed. The question was: 'How likely is it that you will spend your main vacation at the destinations listed below if things develop as described in the next few years?' A list with a total of 24 holiday destinations ( 8 German regions, 13 regions in the rest of Europe, North Africa, USA/ Canada and other countries) was presented to subjects. The destinations 'North Sea (former West Germany)', 'Baltic Sea (former West Germany)' and 'Baltic Sea (former East Germany)' were on the top of the list. Subjects rated each destination with a 4-point scale ranging from 1 (very unlikely) to 4 (very likely).

\section{RESULTS}

\subsection{M anipulation checks}

In general the subjects had no difficulties in picturing the scenarios (mean rating $=1.99=$ easy). An analysis of variance ${ }^{1}$ (ANOVA) revealed that there were no differences in how easily subjects were able to imagine the respective scenarios among experimental conditions.

The following manipulation check was carried out to find out if subjects thought the described changes were more positive or negative for the respective regions and world-wide. It was expected that the positive scenarios would differ from the negative scenarios only for manipulation check 1 , where subjects judged from a regional point of view (cf. Table 1).

The single factor ANOVA for the manipulation check 1 (regional) yielded a significant effect $(p<$ 0.001). The outcome of the ANOVA for manipulation check 2 (global rating) was also significant ( $p<0.001$ ).

The results of the manipulation checks are as follows: Both groups with the positive scenarios rated the regional situation more negatively compared to the control group. For the 2 groups with the negative scenarios, the ratings of the regional situation were significantly more negative than those of the positive scenario groups. In the judgement of the world-wide situation, all 4 scenario groups varied significantly from the control group. The difference between the 2 groups with the positive scenario and the 2 groups with the negative one was much less pronounced.

\section{2. $H$ ypotheses test}

The likelihood of taking a vacation at 1 of the 3 destinations at the German coast following treatment was the dependent variable. The items 'N orth Sea (former West Germany)', 'Baltic Sea (former West Germany)'

\footnotetext{
${ }^{1}$ ANOVA is a method to test the null hypothesis, i.e. the assumption that there are no differences between the mean values of different groups $\left(\mathrm{H}_{0}=\mu_{1}=\mu_{2}=\mu_{3}=\ldots\right)$. The $\mathrm{p}$-values are the probabilities of rejecting the null hypothesis erroneously (cf. Bortz 1979, 1984)
} 
Table 1. M eans of positive or negative ratings of the situation in the described scenario (the higher the value, the more negative the rating, scale ranges from 1 to 5). Neg., pos.: negative or positive climate change effects; without, with: without or with tourism industry response. $n$ : number of ratings. Means with the same letter in the same row differ significantly, 1-sided t-test (e.g. the occurrence of the letter $\mathrm{f}$ in the lower row twice indicates that the ratings with respect to the global situation under the conditions neg. / without and pos. / with deviate significantly)

\begin{tabular}{|lccccc|}
\hline & $\begin{array}{c}\text { Control group } \\
\mathrm{n}=28\end{array}$ & $\begin{array}{c}\text { Neg./ without } \\
\mathrm{n}=22\end{array}$ & $\begin{array}{c}\text { Neg./ with } \\
\mathrm{n}=27\end{array}$ & $\begin{array}{c}\text { Pos. / without } \\
\mathrm{n}=29\end{array}$ & $\begin{array}{c}\text { Pos./ with } \\
\mathrm{n}=29\end{array}$ \\
\hline Regional & $2.86 \mathrm{abcd}$ & $4.36 \mathrm{ceg}$ & $4.25 \mathrm{dfh}$ & 3.68 aef & $\begin{array}{l}3.38 \mathrm{bgh} \\
4.17 \mathrm{bf}\end{array}$ \\
World-wide & $3.11 \mathrm{abcd}$ & $4.62 \mathrm{cef}$ & $4.36 \mathrm{~d}$ & $4.17 \mathrm{ae}$ & \\
\hline
\end{tabular}

and 'Baltic Sea (former East Germany)' were combined to form 1 scale (mean of the 3 items). The internal consistency of this scale is very high (Cronbach's $\alpha=0.95)$. Thus, one can suppose that the assessment of the likelihood of choosing the German coastal area is reliable. This index was used as the dependent variable and entered in the ANOVA. The single-factor ANOVA yielded significant results $(p<0.001)$. Results are presented in Table 2.

Hypothesis 1 assumed that the reported likelihood of visiting a particular region increases in the case of a positive scenario in comparison to a control group. It was not possible to confirm this hypothesis because the difference between the 2 means 2.21 and 2.28 is not significant. As the results of the manipulation checks of the judgements of regional effects showed, the positive scenarios were indeed perceived in a more favourable light than the negative ones; however, they were still less positive than those of the control group.

Hypothesis 2 stated that the reported likelihood of choosing a destination decreases in the case of negative scenarios. This hypothesis can be confirmed, since the means of the 2 groups with the negative scenario differ from the mean of the control group.

Hypothesis 3 stated that appropriate measures taken by the tourism industry can compensate for the adverse effects of negative scenarios. To confirm this hypothesis, the mean of the negative scenario/tourism industry response group would have to be significantly higher than the mean of the negative scenario/no tourism industry response group. Since this is not the case, Hypothesis 3 must be rejected.

An additional observation may be worth mentioning: the reported likelihood of visiting the North German coastal region decreased under the condition 'positive climate change effect with tourism industry (re)action' (1.82) compared to the condition 'positive climate change effect without tourism industry'
(2.28). One can assume that if the tourism industry tries to capitalise too much on a positive development of the climate by overloading the region with tourist facilities a sort of boomerang effect might occur.

This boomerang effect is probably related to the North German coast's suitability for relaxation purposes. The suitability varies among the scenarios. Tourists with a rather strong motivation for rest and relaxation will show a stronger desire to spend holidays in German coastal areas if they expect to find a social and natural environment allowing for rest and relaxation. If they do not expect to find such an environment, the desire to travel to the shores of Northern Germany will be weaker. The respective correlations for each experimental condition are presented in Table 3.

As indicated in Table 3, the expected positive correlations were found for the control group and for the positive scenario without tourism industry response. However, the correlation disappears if a favourable development of the climate leads the tourism industry to take measures which threaten to turn the coastal region into a mass tourism area. Likewise, there no

Table 2. Likelihood of choosing the North German coast as vacation destination. Scenario abbreviations and $\mathrm{n}$ as in Table 1 . Means with the same letter in the same row differ significantly, 1-sided t-test

\begin{tabular}{|ccccc|}
\hline Control group & Neg./ without & Neg./ with & Pos./ without & Pos./ with \\
\hline$n=28$ & $n=22$ & $n=27$ & $n=29$ & $n=29$ \\
$2.21 \mathrm{abc}$ & $1.47 \mathrm{be}$ & $1.54 \mathrm{cf}$ & $2.28 \mathrm{def}$ & $1.82 \mathrm{ad}$ \\
\hline
\end{tabular}

Table 3. Correlations between the strength of the relaxation motive and the likelihood of choosing the N orth German coast as destination for main vacation. M eans with the same letter differ significantly (z-test for differences between correlations, 1-sided). *p $<0.05, * * p<0.01$

\begin{tabular}{|ccccc|}
\hline Today & Neg./ without & Neg./with & Pos./ without & Pos./with \\
\hline $\mathrm{n}=28$ & $\mathrm{n}=22$ & $\mathrm{n}=27$ & $\mathrm{n}=29$ & $\mathrm{n}=29$ \\
$0.38^{*} \mathrm{a}$ & $-0.07 \mathrm{~b}$ & $0.31 \mathrm{c}$ & $0.59^{* *} \mathrm{~b}$ & $-0.14 \mathrm{abc}$ \\
\hline
\end{tabular}


longer is a relationship between the relaxation motive and destination choice in the negative scenario. However, the coast's suitability for relaxation purposes appears to be restored in some way through the (re)actions of the regional tourism industry in the negative scenario.

\section{DISCUSSION}

The results of the pilot study presented here should be discussed from 2 perspectives: methodology and preliminary results.

From a methodological point of view the experiences made give evidence that this kind of approach is suitable for further (and more in depth) research: subjects had no trouble imagining the scenarios, the manipulation checks indicate differences, and differences between conditions were also found in the dependent variables. Thus, the adopted procedure appears promising and can be applied in future studies.

Nevertheless, some improvements are possible. First, the scenarios should be formulated more precisely in reference to meteorological terms and should be brought closer into line with current knowledge of climate change. The description of the (re)action strategies of the tourism industry should be more precise as well. One must be careful to word the reactions in such a way that they are realistic enough for subjects to imagine (ecological validity). The design of further experimental studies should be more differentiated (e.g. extent of destruction to nature).

Besides the relaxation motive, a number of other person variables could be worth considering; these could be entered in the experimental design as quasi-factors, such as demographic variables, subjects' sensitivity to climate, or preferred type of countryside. It may also be a good idea to consider the particular interview situation (How was the weather at time of interview? What are the media currently reporting on climate change?).

Finally, the size and composition of the sample in the pilot study were not designed to produce reliable data on a representative base. The subsequent main study should ensure that the sample is sufficiently representative and large enough.

Besides the findings with regard to the methodological aspects, within the restricted possibilities of a pilot study we have gained first ideas on whether and in which direction the effects of an eventual climate change may influence destination choice of tourists. According to the data, climate change can influence the preferences for vacation destinations. In respect to the N orth German coastal region, this effect is rather a negative one, i.e. under climate change conditions as presented in the scenarios possible tourists are less eager to travel there than under today's conditions.

It will not be easy for the local and regional tourism industry to reduce negative effects or to use positive effects to a certain extent by appropriate action. Within limits the possibility may exist, but one has to be rather careful in defining what is 'appropriate', e.g. with respect to their target groups in tourism.

The results do not allow for predictions of destination choice (will really go there) or behaviour patterns during holidays (e.g. will do less sailing) under climate change conditions; they just point to the relationship of natural attractiveness of a destination (and weather conditions are an important part of this), amenities (or facilities) for tourism, and attitudes towards this destination, which can be influenced by climate change effects and the action taken by the tourism industry to cope with these effects (cf. Holloway 1994, p. 6, Lohmann et al. 1998, p. 68).

The experimental method described here may be one additional tool to the many others used to gain a clearer picture of the possible future of tourism in coastal areas under climate change conditions. For a better understanding we need more detailed data on possible weather characteristics. Does, for example, a rise in air temperature mean that it will be warmer all around the year, winter and summer, day and night? Or is there a certain structure in the course of the year? The availability of climate change data on a smaller geographical scale would be very helpful as well. The relation between weather and tourism and leisure behaviour is worth a closer look. And finally more research on the role of social processes (perception, impact of media, political decisions, etc.) in a society facing a climate change process with a great deal of uncertainty is urgently needed.

Acknowledgements. The Bundesministerium für Bildung, Wissenschaft, Forschung und Technologie (German M inistry of Education, Science, Research, and Technology) supported this research (support No. 01 KJ 9505/2). We thank Hans von Storch for his comments on an earlier draft of the manuscript.

\section{LITERATURE CITED}

Abegg B (1996) Klimaänderung und Tourismus-Klimafolgenforschung am Beispiel des Wintertourismus in den Schweizer Alpen. VDF Hochschulverlag der ETH Zürich, Zürich

Adams DL (1973) Uncertainty in nature, cognitive dissonance, and the perceptual distortion of environmental informations: weather forecasts and N ew England beach trip decisions. Econ Geogr 4:287-297

Aderhold P (1997) Kurzfassung der Reiseanalyse '96. Forschungsgemeinschaft Urlaub und Reisen, Hamburg

Aderhold P (1998) Kurzfassung der Reiseanalyse '97. Forschungsgemeinschaft Urlaub und Reisen, Hamburg 
Bortz J (1979) Lehrbuch der Statistik. Springer, Berlin

Bortz J (1984) Lehrbuch der empirischen Forschung. Springer, Berlin

Braun OL, Lohmann M (1989) Die Reiseentscheidung: einige Ergebnisse zum Stand der Forschung. Studienkreis für Tourismus, Starnberg

Clawson M (1966) The influence of weather on outdoor recreation. In: Sewell W (ed) Human dimensions of weather modification. Department of Geography, University of Chicago, Research Paper No. 105, p 183-193

de Freitas CR (1990) Recreation climate assessment. Int J Climatol 10:89-103

Feige M, Kirchhoff M, Seidel A (1998) Küstentourismus in Deutschland: eine Standortbestimmung. Tourismusjournal 1:51-65

Forschungsgemeinschaft Urlaub und Reisen (1996) Reiseanalyse 1996. Forschungsgemeinschaft Urlaub und Reisen, Hamburg

Hahn H, Hartmann KD (1973) Reiseinformation, Reiseentscheidung, Reisevorbereitung. Studienkreis für Tourismus, Starnberg

Hartmann KD (1978) Urlaubsreisen 1978. Psychologische Leitstudie. Studienkreis für Tourismus, Starnberg

Holloway J C (1994) The business of tourism. Pitman, London

Editorial responsibility: Hans von Storch,

Geesthacht, Germany
Houghton JT, Meira Filho LG, Callander BA, Harris N, Kattenberg A, Maskell K (eds) (1996) Climate change 1995. The science of climate change. Cambridge University Press, Cambridge

Krupp C (1995) Klimaänderungen und die Folgen. Ed Sigma, Berlin

Lohmann M, Wohlmann R (1987) Urlaub in Deutschland. Studienkreis für Tourismus, Starnberg

Lohmann M, Kierchhoff HW, Kaim E, Warncke K (1998) Küstentourismus in Deutschland: Nachfragestruktur und die Anfälligkeit für Klimaänderungen. Tourismusjournal 1 : 67-79

Mundt J W, Lohmann M (1988) Erholung und Urlaub. Studienkreis für Tourismus, Starnberg

Pivonas G (1980) Reiseentscheidung. Eine Verlaufsanalytische Untersuchung. Studienkreis für Tourismus, Starnberg

Purucker HK (1986) Urlaubsreisen 1986-psychologische Leitstudie Reisezufriedenheit-Berichtsband. Studienkreis für Tourismus, Starnberg

Stehr N, von Storch H (1995) The social construct of climate and climate change. Clim Res 5:99-105

Van Raaij F, Francken DA (1984) Vacation decisions, activities, and satisfactions. Ann Tourism Res 11:101-112

Submitted: October 30, 1997; Accepted: December 25, 1998 Proofs received from author(s): A pril 20, 1999 